\title{
A Budget Impact and Cost Per Additional Responder Analysis for Baricitinib for the Treatment of Moderate-to-Severe Rheumatoid Arthritis in Patients with an Inadequate Response to Tumor Necrosis Factor Inhibitors in the USA
}

\author{
Elizabeth Wehler ${ }^{1}$ (i) $\cdot$ Natalie Boytsov ${ }^{2} \cdot$ Claudia Nicolay $^{3} \cdot$ Oscar Herrera-Restrepo $^{4} \cdot$ Stacey Kowal $^{4}$
}

Published online: 27 August 2019

(c) The Author(s) 2019

\begin{abstract}
Background/Objective Baricitinib is a selective and reversible Janus kinase (JAK) inhibitor indicated for the treatment of adult patients with moderately to severely active rheumatoid arthritis (RA) who have had an inadequate response to one or more tumor necrosis factor inhibitors (TNFis) and has been shown to improve multiple clinical and patient-reported outcomes. However, it is unclear what the budgetary impact would be for US commercial payers to add baricitinib to their formulary and how the efficacy of baricitinib compares to other disease-modifying antirheumatic drugs (DMARDs) with a similar indication.

Methods A budget impact model (BIM) was developed for a hypothetical population of 1 million plan members that compared a world without and with baricitinib. A retrospective observational study was carried out to estimate market utilization of advanced therapies. Number needed to treat (NNT) and cost per additional responder were calculated for American College of Rheumatology (ACR) 20\%/50\%/70\% improvement criteria (ACR20/50/70) response outcomes combining cost estimates from the BIM and efficacy values from a network meta-analysis (NMA). The model included costs related to drug acquisition and monitoring costs.

Results Adding baricitinib would save a commercial payer \$US169,742 for second-line therapy and \$US135,471 for thirdline therapy over a 2-year time horizon (all costs correspond to 2019 US dollars). Cost savings were driven by baricitinib drawing market share away from more expensive comparators. The NMA, based on nine studies, found no statistically significant differences in the median treatment difference between baricitinib and comparators except for versus a conventional synthetic DMARD (csDMARD), and thus NNT versus a csDMARD was similar. The cost per additional responder for baricitinib in patients with inadequate response to a TNFi was substantially lower than all other treatments for all three ACR response criteria at 12 weeks (ACR20: \$US129,672; ACR50: \$US237,732; ACR70: \$US475,464), and among the lowest at 24 weeks (ACR20: \$US167,811; ACR50: \$US259,344; ACR70: \$US570,557).

Conclusions Baricitinib, compared to other DMARDs, was a less expensive option ( $\$$ USO.01 incremental cost per member per month in second- and third-line therapy over a 2-year time horizon) with comparable efficacy in patients with inadequate response to TNFi. Adding baricitinib to formulary would likely be cost saving for US payers and expands treatment options for these patients.
\end{abstract}

\section{Introduction}

Electronic supplementary material The online version of this article (https://doi.org/10.1007/s40273-019-00829-x) contains supplementary material, which is available to authorized users.

Elizabeth Wehler

beth.wehler@iqvia.com

Extended author information available on the last page of the article
Rheumatoid arthritis (RA) is a systemic and chronic inflammatory disease of unclear etiology [1]. It leads to a progressive and destructive polyarthritis and is characterized by chronic pain and joint destruction that usually progress from distal to more proximal joints [1]. RA affects approximately 1.3 million people in the USA [2].

In the last decade, management of RA patients has shifted from controlling symptoms to preventing and controlling 


\section{Key Points for Decision Makers}

Baricitinib is a less expensive treatment option for rheumatoid arthritis (RA) patients who have had an inadequate response to one or more tumor necrosis factor inhibitors and shows similar efficacy to other treatment options.

The cost per additional responder was lowest for baricitinib at 12 weeks and among the lowest at 24 weeks.

Use of baricitinib could lower RA treatment costs from a healthcare payer perspective and provides an additional treatment option for patients.

damage [3]. With the availability of biologic disease-modifying antirheumatic drugs (bDMARDs), which includes tumor necrosis factor (TNF) inhibitors (TNFis) and nonTNFis, and targeted synthetic disease-modifying antirheumatic drugs (tsDMARDs), which includes Janus kinase (JAK) inhibitors, treatment guidelines recommend a 'treatto-target' approach in which the goals of treatment are to target remission or low disease activity and maintain remission [4]. Recommendations suggest patients begin with diseasemodifying antirheumatic drug (DMARD) monotherapy, and, should disease activity remain moderate or high, switch to combination traditional DMARDs, or add a TNFi, non-TNF biologic, or tofacitinib [4]. This approach has been shown to lead to better health outcomes and quality of life [3].

Despite the availability of various treatment options and evidence supporting early and aggressive treatment, there are still significant challenges in the current management of patients with RA [4, 5]. For example, many patients have an inadequate response (IR) to their treatment, which can include lack of efficacy and/or treatment intolerance $[4,6]$. Barriers to optimizing treatment exist for both patients and physicians, which can delay the use of new treatment options and thus increase the risk of irreversible joint damage. For inadequate responders, dose escalation of TNFis provides minimal clinical benefit and may increase the risk of adverse events (AEs) [7]. Furthermore, when an incomplete response to TNFis occurs, cycling through treatments of the same mechanism of action has been shown to result in diminished treatment response [8-11].

The economic consequences resulting from an IR to treatment are substantial, with several studies reporting that patients who have an IR generate approximately twice the total healthcare costs on average than those who do achieve remission or low disease activity [12-15]. Additionally, dosing escalation for biologics are associated with higher total annualized healthcare expenditures [16-18] and switching to another therapy with a different mechanism of action is likely more cost effective than switching from one TNFi to another TNFi [19].

Baricitinib is an oral selective and reversible JAK inhibitor (categorized as a tsDMARD) indicated for the treatment of adult patients with moderately to severely active RA who have had an IR to one or more TNFis [20]. Baricitinib has been shown to be effective in RA patients who have had an IR to one or more TNFis, other bDMARDs, or both [21], with improvement in multiple clinical measures and patientreported outcomes and a rapid onset of action as early as 1 week from baseline compared with placebo [6, 22, 23]. The introduction of baricitinib in the US market broadens the availability of RA treatment choices for TNFi-IR patients, thereby potentially alleviating the burdens already described. However, it is unclear what the budgetary impact would be for US payers to add baricitinib within the context of current market dynamics. Nor is it clear what the comparative effectiveness of baricitinib is relative to treatments with a similar indication.

This study provides results from a budget impact model (BIM) that forecasts the fiscal implications of adding baricitinib to a formulary that already includes several treatment options available in the US (i.e., subcutaneous biologics [etanercept, adalimumab, abatacept, golimumab, tocilizumab, certolizumab pegol, and sarilumab] and JAK inhibitors [tofacitinib]). Comparative effectiveness was determined using number needed to treat (NNT) and cost per additional responder, which leveraged treatment costs from the BIM and American College of Rheumatology (ACR) 20\%/50\%/70\% improvement criteria (ACR20/50/70) response outcomes reported from a network meta-analysis (NMA).

\section{Methods}

\subsection{Estimating the Budgetary Consequences of Adding Baricitinib}

A BIM was developed to estimate the budgetary consequences of the use of baricitinib for the treatment of TNFi-IR patients from the perspective of a US healthcare commercial payer. The model used a comparative cost determination framework where costs were calculated based on a world without and with baricitinib following modeling best practices [24]. The model was developed using Microsoft Office Excel $^{\circledR}$ (Microsoft Corp., Redmond, WA, USA) to estimate the current evidence-based US costs of treating adult patients with moderately to severely active RA who have had an IR to one or more TNFis, as well as to understand the value of baricitinib in RA. 


\subsubsection{Target Population}

To quantify the target population eligible for baricitinib each year, epidemiologic and claims-based studies were leveraged. The model started with a hypothetical population of 1 million plan members, of which 774,000 (77.4\%) were estimated as adults based on 2017 US Census estimates [25]. An annual RA prevalence of $0.53 \%$ [2] and incidence of $0.04 \%$ [26] were applied to arrive at $4420 \mathrm{RA}$ patients in year 1 and 4737 in year 2 . It was assumed that $88.35 \%$ of patients were treated with DMARDs [27], and $19.17 \%$ of them were treated with TNFis [28]. The model also considered that $47.5 \%$ had an IR (ESM Online Resource Table 3) [29].

\subsubsection{Market Utilization}

A retrospective observational study using data from the Truven Health MarketScan Research data warehouse was conducted to assess market share of advanced therapies in RA by line of therapy, including TNFis (adalimumab, certolizumab pegol, etanercept, golimumab, and infliximab), nonTNFis (abatacept, rituximab, sarilumab, tocilizumab, and anakinra), and JAK inhibitors (tofacitinib). The line of therapy was determined by evaluating the number of advanced therapies prior to the index therapy during a 6-year history. Data retrieval focused on the period from 1 January 2017 to 31 December 2017. Patients included in the analysis were selected based on criteria shown in Fig. 1. After applying the inclusion/exclusion criteria, 20,384 patients were included in the analysis. See Electronic Supplementary Material (ESM) Online Resource Table 1 for patient characteristics of the final sample.

Utilization data stratified by line of therapy were used in the BIM to explore budgetary implications of treatments either by second-line after a conventional synthetic DMARD (csDMARD) (after TNFi use) or third-line after a csDMARD (after TNFi and use of another advanced therapy). Table 1 shows the market utilization data that were used in the BIM. The output from the claims-based study was reweighted to only include the comparators of interest.

To calculate future market utilization, it was assumed that baricitinib would take market shares equi-proportionally from all included market comparators. The market uptake of baricitinib was forecasted by the manufacturer anchored to the market share of tofacitinib at launch (i.e., not current uptake), the other comparator in its class. In addition to the market utilization retrieved from the claims-based study, the BIM also allowed methotrexate to be used as combination therapy. By default, the model assumed that $65 \%$ of patients on non-csDMARDs regimens used methotrexate while the remaining 35\% received monotherapy [30,31]. Additionally, the BIM assumed that $88.8 \%$ of methotrexate users (used in combination with primary therapy) received methotrexate orally with the remainder receiving intravenous methotrexate. This value was derived from claims data and provided by the manufacturer.

\subsubsection{Cost and Resource Use}

The model calculated the total annual cost per patient by summing costs related to drug acquisition and monitoring costs (Table 2). All costs correspond to 2019 US dollars. The model assumed all administration was self-administered (subcutaneous or oral treatments) and therefore no administration costs were applied [32-40]. Drug acquisition costs for all treatments were calculated based on drug dosing and unit costs (2019 Wholesale Acquisition Cost) data from Medispan Price Rx [41]. In the base case, rebates were assumed to be zero and patient cost sharing and dispensing fees were not included. Dosing was based on product prescribing information (PI) and accounted for loading doses or altered dosing patterns when patients first initiate therapy as well as dose escalation based on published literature (ESM Online Resource Table 2). Dose escalation was assumed to occur 6 months after treatment initiation and patients were assumed to continue at the escalated dose for the duration of the model [36, 42-45].

Per the ACR RA guidelines and product PIs, patients on RA treatment require safety monitoring, which can be broken into four time periods: baseline, $<3$ months, 3-6 months, and 6-12 months. For each timeframe, and for each treatment, a set of required monitoring resources were itemized and unit costs applied. Resource use in the 6- to 12-month range was assumed to apply for the duration of the model. Given limited data availability for the commercial perspective, physician fees and laboratory fees were based on national payment rates per the Centers for Medicare Services (CMS) physician fee schedule and the CMS laboratory fee schedule [46, 47]. A summary of inputs used in the BIM is provided in the ESM Online Resource Tables 3 and 4.

AEs were not included in the model for several reasons. First, AEs have not been found to be significant model drivers in previous RA health technology assessments and have sometimes been excluded given the assumption that there is no difference in the safety profiles of bDMARDs [48]. Second, a previously published BIM in RA excluded AEs due to heterogeneity in AE reporting [49]. Finally, even if AEs were included, the RA-BEACON trial results show that the impact would be low [6]. 


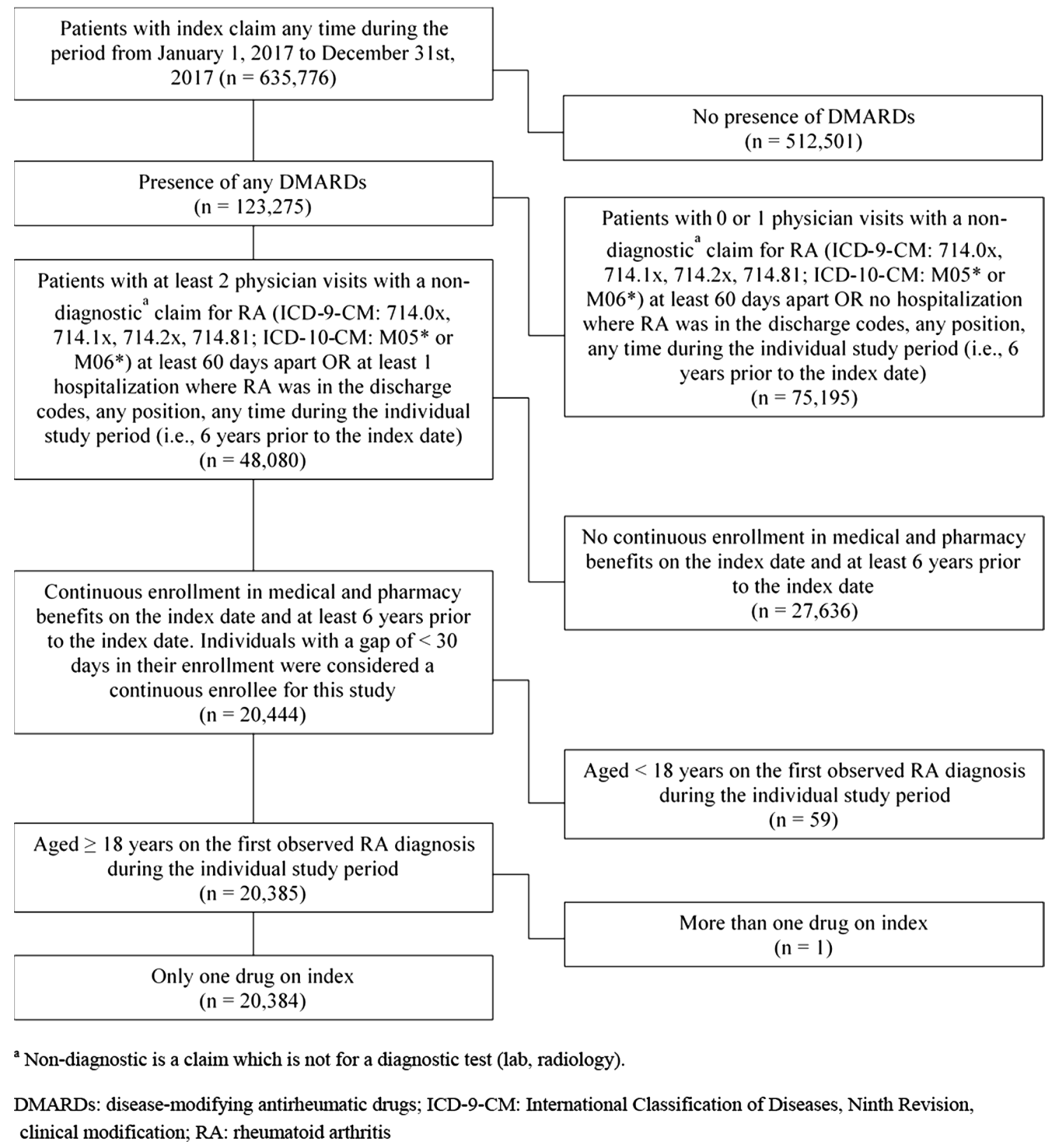

Fig. 1 Claims-based study criteria. ${ }^{a}$ Non-diagnostic is a claim that is not for a diagnostic test (laboratory, radiology). DMARDs diseasemodifying antirheumatic drugs, ICD-9-CM International Classification of Diseases, Ninth Revision, Clinical Modification, ICD-10-CM

\subsection{Response Rates for Number Needed to Treat (NNT) and Cost per Additional Responder: Systematic Literature Review and Network Meta-Analysis}

ACR20/50/70 response rates were derived from a systematic literature review (SLR) and NMA. The SLR and NMA aimed to identify and synthesize clinical effectiveness evidence of treatments for the moderate-to-severe TNFi-IR
International Classification of Diseases, Tenth Revision, Clinical Modification, $R A$ rheumatoid arthritis. Asterisk represents any subsequent codes under the particular major code heading

RA patients from randomized controlled trials published between 1999 and December 2017. While the SLR and NMA included a full spectrum of treatments, the NNT and cost per additional responder calculations presented here include only subcutaneous or oral treatments relevant to the USA. Furthermore, safety endpoints were not included as part of the NMA, as most studies allowed the use of rescue therapy for the control arm if a certain treatment response was not observed. In general, safety endpoints are only 
Table 1 Estimated market share data from the claims-based study

\begin{tabular}{lcc}
\hline Treatment option $^{\mathrm{a}}$ & Second line (\%) & Third line (\%) \\
\hline Abatacept & 15.5 & 24.1 \\
Adalimumab & 26.7 & 8.9 \\
Certolizumab pegol & 5.4 & 7.7 \\
Etanercept & 21.5 & 7.9 \\
Golimumab & 7.3 & 9.2 \\
Sarilumab & 0.0 & 0.0 \\
Tocilizumab & 8.7 & 16.6 \\
Tofacitinib & 14.9 & 25.6 \\
Total & 100.0 & 100.0 \\
\hline
\end{tabular}

csDMARD conventional synthetic disease-modifying antirheumatic drug, TNFi tumor necrosis factor inhibitor

${ }^{a}$ Utilization data stratified by line of therapy were used in the budget impact model to explore budgetary implications of treatments either by second line after csDMARD (after TNFi use) or third line after csDMARD (after TNFi and use of another advanced therapy)

reported for the whole duration of the study and not at intermediate endpoints, such as week 12. As a result, reporting of, for example, discontinuation and AEs are confounded with the occurrence of rescue therapy. The details of the SLR can be found in ESM Online Resources Tables 5, 6, and Fig. 1. In summary, a total of 10,008 citations were identified after removing duplicates and were screened for inclusion, of which 322 studies were included in the SLR. These 322 studies consisted of a mix of RA populations including csDMARD-naive, csDMARD including methotrexate IR (MTX-IR), MTX-IR, and TNFi-IR patients. Of these, only nine studies included the TNFi-IR population and met the inclusion criteria for the NMA (Table 3) [6, 50-76]. The quality assessment of studies was performed to standards recommended by the National Institute for Health and Care Excellence (NICE) and the Centre for Reviews and Dissemination [77, 78].
The NMA estimated between-treatment differences in ACR20/50/70 response (median difference, 95\% credible interval [Cr-Int]). A Bayesian mixed-treatment comparison using a simultaneous model consisting of baseline and treatment effects was conducted as described in the NICE Decision Support Unit (DSU) [79]. Fixed- and random-effect models were fitted. However, random-effect models were unstable and did not converge, and therefore fixed-effects models were chosen as the primary approach. Extensive sensitivity analyses were pre-planned. Given the limited number of studies, only independent baseline models and frequentist models could be performed. The main analyses are presented for the 12- and 24-week timepoints as the median difference in ACR20, ACR50 and ACR70 response rates, and only consider the $2 \mathrm{mg}$ dose of baricitinib, which is the dose approved in the USA. For the NNT and cost per additional responder calculations, results from the probit simultaneous fixed-effects models were used. See Table 4 for a description of the baseline characteristics of the studies included in the NMA and ESM Online Resource Fig. 2 for further details on the NMA results.

\subsubsection{NNT and Cost per Additional Responder}

NNT and cost per additional responder were calculated for the ACR20/50/70 response at 12 and 24 weeks. The ACR criteria measure response to treatment, defined by both improvement in the number of tender and number of swollen joints, and improvement in three of the following five criteria: patient's global assessment, physician's global assessment, functional ability measure, visual analog pain scale, and erythrocyte sedimentation rate or C-reactive protein [80, 81]. A response of ACR20/50/70 corresponds to a percentage improvement between two timepoints. The treatments in the NNT and cost per additional responder calculations focused only on those products that compete directly with
Table 2 Total annual costs by treatment per patient

\begin{tabular}{|c|c|c|c|c|c|c|}
\hline \multirow[t]{3}{*}{ Treatment option } & \multicolumn{6}{|c|}{ Annual costs per patient (\$US; 2019 values) } \\
\hline & \multicolumn{2}{|c|}{ Treatment $^{\mathrm{a}}$} & \multicolumn{2}{|c|}{ Monitoring } & \multicolumn{2}{|l|}{ Total } \\
\hline & Year 1 & Year 2 & Year 1 & Year 2 & Year 1 & Year 2 \\
\hline Abatacept & 57,256 & 57,256 & 229 & 94 & 57,485 & 57,349 \\
\hline Adalimumab & 72,768 & 72,768 & 260 & 128 & 73,027 & 72,896 \\
\hline Baricitinib & 28,110 & 28,110 & 240 & 94 & 28,350 & 28,204 \\
\hline Certolizumab pegol & 65,242 & 56,587 & 292 & 128 & 65,534 & 56,715 \\
\hline Etanercept & 72,767 & 72,767 & 260 & 128 & 73,027 & 72,895 \\
\hline Golimumab & 62,848 & 62,848 & 260 & 128 & 63,107 & 62,976 \\
\hline Sarilumab & 86,735 & 86,735 & 255 & 123 & 86,990 & 86,859 \\
\hline Tocilizumab & 26,918 & 27,902 & 255 & 123 & 27,173 & 28,026 \\
\hline Tofacitinib & 58,579 & 58,579 & 240 & 94 & 58,818 & 58,672 \\
\hline
\end{tabular}

${ }^{\text {a }}$ The annual costs presented here assume $88.8 \%$ methotrexate use in combination with the primary therapy based on manufacturer data from a claims analysis 


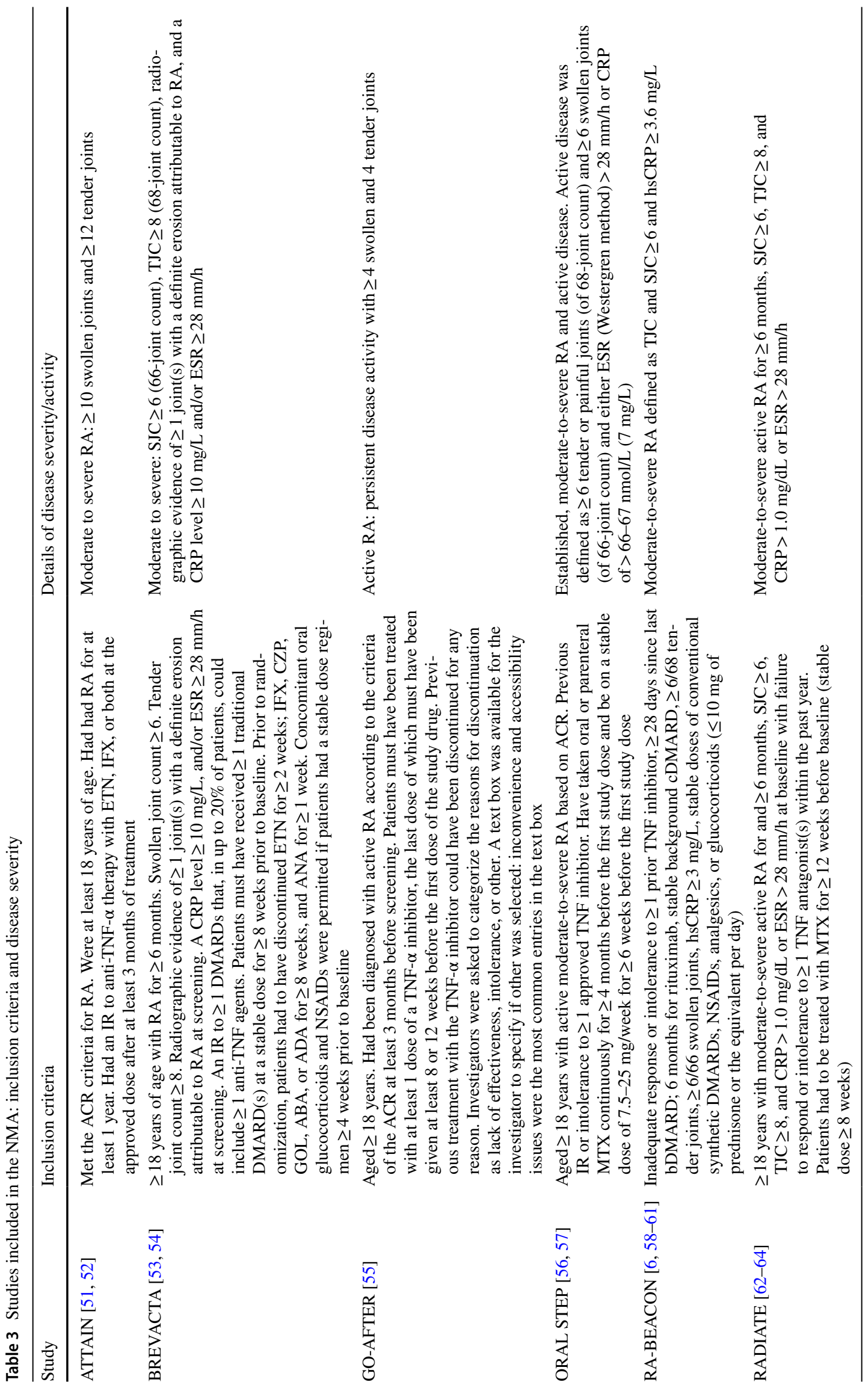




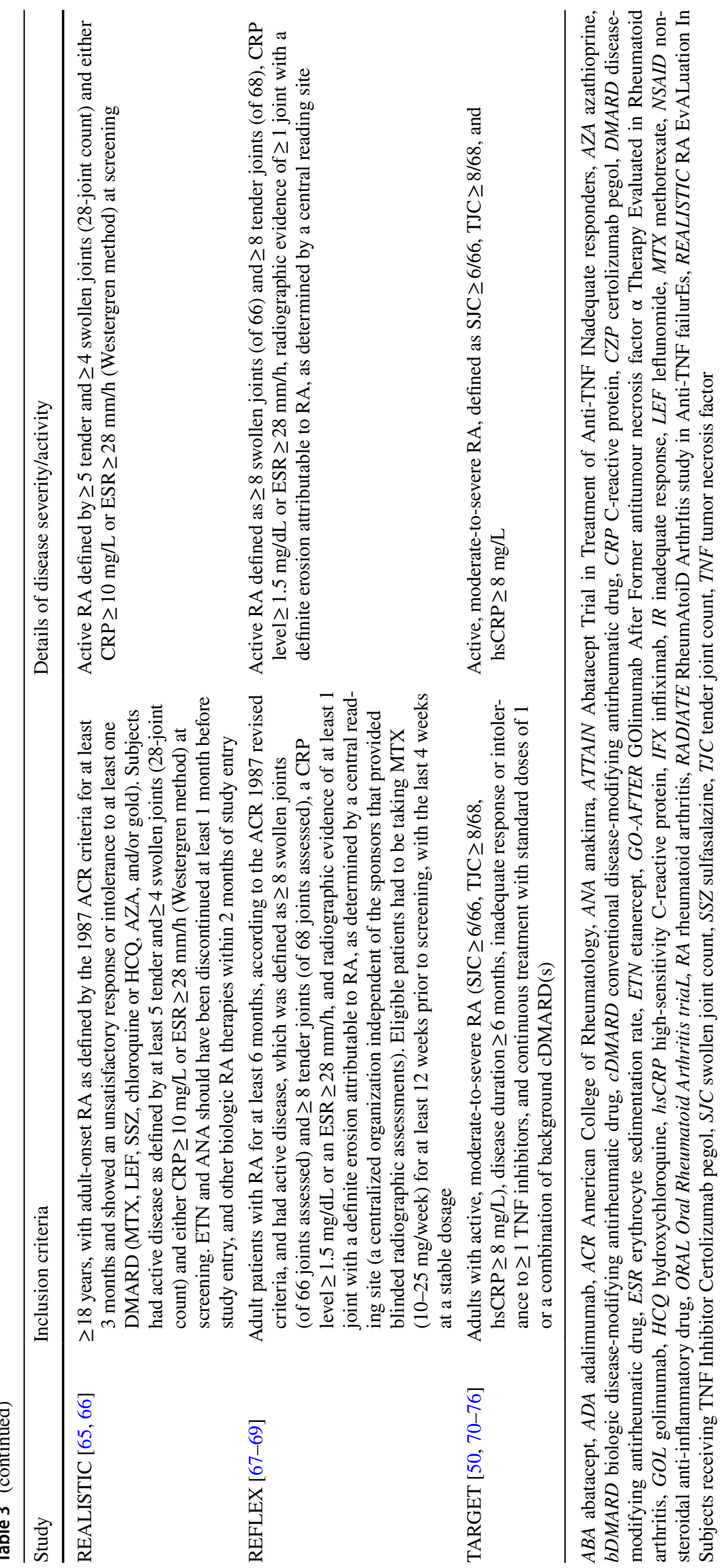


baricitinib and are listed in Table 5. Note that for some comparators only either 12- or 24- week trial endpoints were available for the NMA.

The NNT was calculated as the inverse of the difference in response rate between each treatment and csDMARD at 12 and 24 weeks (i.e., 1/[Intervention - csDMARD]). Cost per additional responder was calculated as the first-year cost of each treatment, as derived from the BIM, multiplied by the NNT versus csDMARD. The first-year costs assumed all patients on each treatment were also taking methotrexate to match the clinical data used in the NMA.

\subsection{BIM Base-Case and Sensitivity Analyses}

The BIM considered two base-case scenarios as derived from the claims-based study market utilization: Base Case 1market share for second-line therapy after csDMARD; and Base Case 2-market share for third-line therapy after a csDMARD. Since baricitinib can be used for patients who have an IR to one or more TNFis, it can be used across multiple lines of downstream treatment. For each scenario, the model calculated total costs, cost per member per month (PMPM), cost per member per year, cost per patient per month, and cost per patient per year over a 2-year time horizon.

A one-way sensitivity analysis was conducted for all parameters, including inputs for market adoption, epidemiology, dose escalation, and administration. These variables were varied by $20 \%$ iteratively. In addition, a scenario with updated 2018 Early View MarketScan data for populating market shares was considered.

All analyses were from the US commercial healthcare payer perspective.

\section{Results}

\subsection{Budget Impact Analysis Results: Base Case}

Based on the population cascade estimates, 356 patients were eligible for baricitinib in year 1 and 381 patients were eligible in year 2, an increase of 25 due to the inclusion of incident patients in year 2 . Given the projected market share of baricitinib $(0.2 \%$ in year $1,1.1 \%$ in year 2$)$, the number of baricitinib-treated patients in each year was relatively low, with one and four patients in a hypothetical 1 millionmember plan, respectively. The addition of baricitinib for the treatment of moderate-to-severe RA for patients with an IR to TNFi therapy would be cost saving to the commercial payer (net budget impact: - \$US169,742 [-0.37\%] for second-line therapy after a csDMARD and - \$US135,471 [-0.33\%] for third-line therapy after a csDMARD; Table 6).
The cost saving result in both the second-line and third-line was driven by baricitinib drawing market shares away from more expensive comparators. Third-line market shares produced slightly lower cost savings than second-line market shares as patients were assumed to have higher use of inexpensive therapies with less use of products such as adalimumab and etanercept. Nonetheless, both scenario results showed that shifting to a less expensive therapy option (baricitinib) produced cost savings.

\subsection{NNT and Cost per Additional Responder}

The NMA found that there were no statistically significant differences in ACR response median treatment differences between baricitinib and the other comparators included in this analysis at weeks 12 and 24 except for versus csDMARD (see Fig. 2).

Table 5 presents the NNT versus csDMARD and cost per additional responder per treatment. The NNT was lowest overall for ACR20 than for ACR50 and ACR70, which reflects the declining response rate with an increasing threshold for response. At 12 weeks, the NNT did not differ considerably within each response criteria, ranging from 3.9 to 5.3 for ACR20, 6.3 to 10.0 for ACR50, and 12.5 to 20.0 for ACR70. Similarly, at 24 weeks the NNT did not differ considerably for ACR20 (range of 3.3-5.9) and ACR50 (range of 4.8-9.1), although for ACR70 there was a wider range of NNT values (9.1-20.0). Given that the median treatment difference was not statistically significantly different for baricitinib versus other comparators (except for a csDMARD), NNT point estimates within each response criteria should be interpreted cautiously. Use of the 95\% Cr-Ints in scenarios to test model sensitivity produced similar trends.

At 12 weeks, the cost per additional responder for baricitinib was substantially lower than for all other treatments for all ACR response criteria. At 24 weeks, tocilizumab had the lowest cost per additional responder followed by baricitinib for ACR20 and ACR50. For ACR70 at 24 weeks, tocilizumab and abatacept had the lowest cost per additional responder followed by baricitinib. Tocilizumab and baricitinib produced the low costs per additional responder due to their relatively low price.

\subsection{Sensitivity Analysis}

Sensitivity analyses revealed that the most influential variables across the results were epidemiological inputs including plan size, percentage adults (target population), percentage treated with DMARDs, percentage treated with first TNFi, and the percentage of patients with TNFi-IR (see Fig. 3 in the ESM Online Resource). However, the model results 


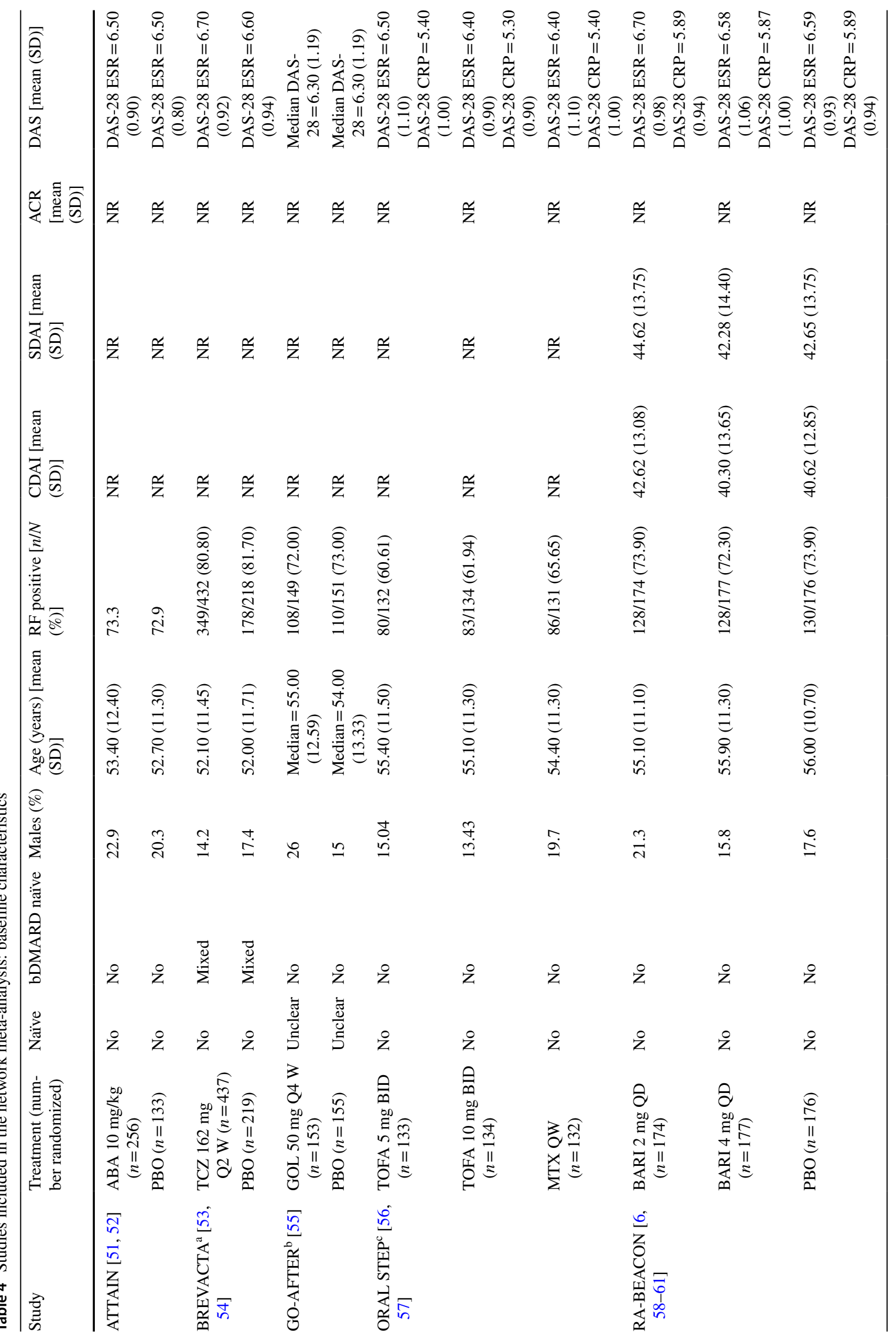




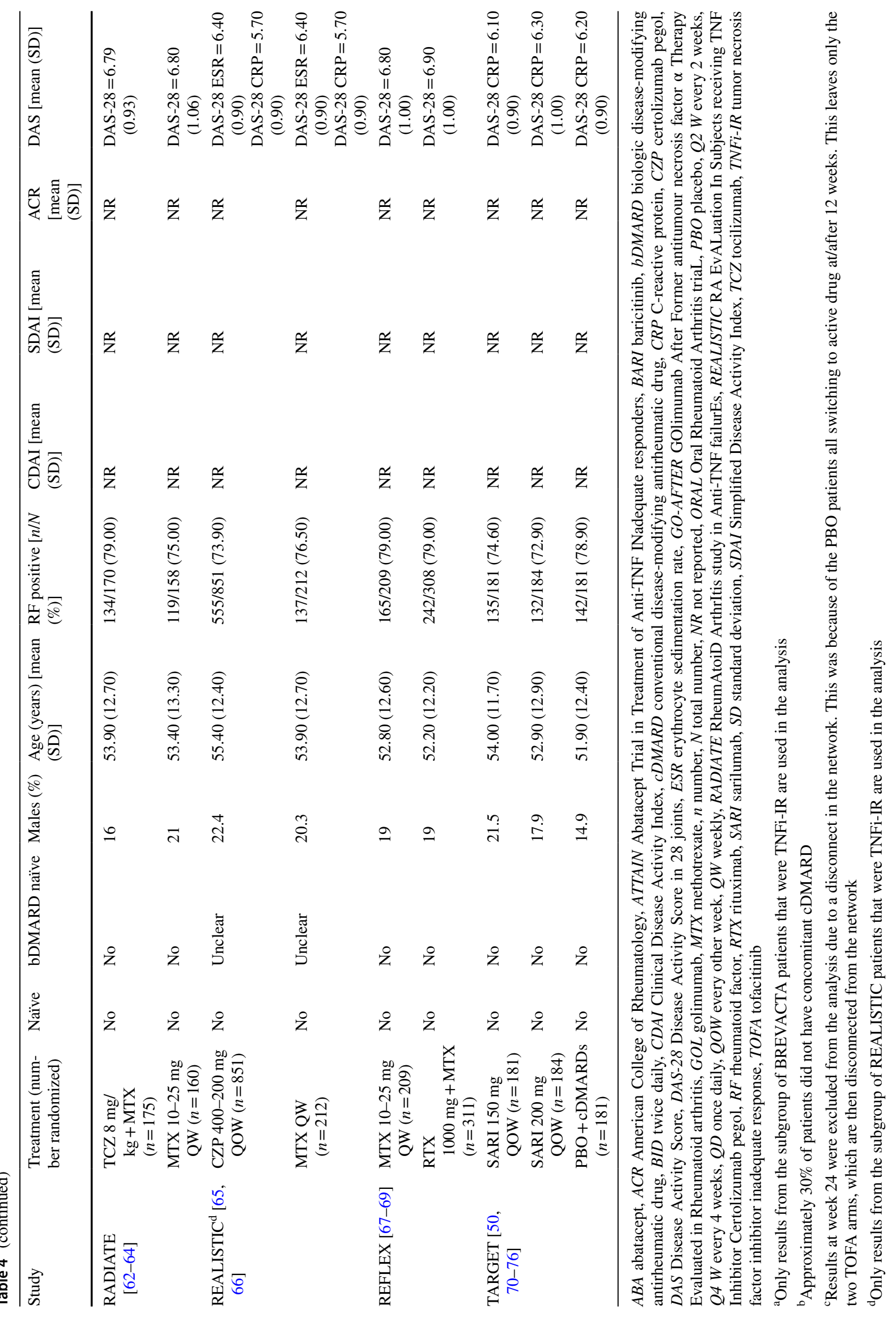


Table 5 Number needed to treat and cost (\$US; 2019 values) per additional responder

\begin{tabular}{|c|c|c|c|c|c|c|c|}
\hline \multirow[t]{2}{*}{ Treatment option } & \multirow{2}{*}{$\begin{array}{l}\text { Annual cost } \\
\left(\$ \text { SS }^{\mathrm{a}}\right.\end{array}$} & \multicolumn{3}{|l|}{12 weeks } & \multicolumn{3}{|l|}{24 weeks } \\
\hline & & $\begin{array}{l}\text { Response } \\
\text { rate }(\%)^{\mathrm{b}}\end{array}$ & $\begin{array}{l}\text { NNT vs. } \\
\text { csDMARD }\end{array}$ & $\begin{array}{l}\text { Cost per additional } \\
\text { responder (\$US) }\end{array}$ & $\begin{array}{l}\text { Response } \\
\text { rate }(\%)^{\mathrm{b}}\end{array}$ & $\begin{array}{l}\text { NNT vs. } \\
\text { csDMARD }\end{array}$ & $\begin{array}{l}\text { Cost per addi- } \\
\text { tional responder } \\
(\$ \cup S)\end{array}$ \\
\hline \multicolumn{8}{|l|}{ ACR20 } \\
\hline Abatacept & 57,663 & 49.0 & 3.85 & 221,782 & 49.0 & 3.45 & 198,839 \\
\hline Adalimumab & 73,205 & NR & N/A & N/A & NR & N/A & N/A \\
\hline Baricitinib & 28,528 & 45.0 & 4.55 & 129,672 & 37.0 & 5.88 & 167,811 \\
\hline Certolizumab pegol & 65,711 & 42.0 & 5.26 & 345,849 & NR & N/A & N/A \\
\hline Etanercept & 73,205 & NR & N/A & N/A & NR & N/A & N/A \\
\hline Golimumab & 63,285 & 43.0 & 5.00 & 316,426 & 41.0 & 4.76 & 301,358 \\
\hline Sarilumab & 87,168 & 49.0 & 3.85 & 335,262 & 44.0 & 4.17 & 363,200 \\
\hline Tocilizumab & 27,350 & NR & N/A & N/A & 50.0 & 3.33 & 91,168 \\
\hline Tofacitinib & 58,996 & 46.0 & 4.35 & 256,506 & NR & N/A & N/A \\
\hline csDMARD & N/A & 23.0 & N/A & N/A & 20.0 & N/A & N/A \\
\hline \multicolumn{8}{|l|}{ ACR50 } \\
\hline Abatacept & 57,663 & 24.0 & 6.25 & 360,395 & 27.0 & 5.00 & 288,316 \\
\hline Adalimumab & 73,205 & NR & N/A & N/A & NR & N/A & N/A \\
\hline Baricitinib & 28,528 & 20.0 & 8.33 & 237,732 & 18.0 & 9.09 & 259,344 \\
\hline Certolizumab pegol & 65,711 & 18.0 & 10.00 & 657,114 & NR & N/A & N/A \\
\hline Etanercept & 73,205 & NR & N/A & N/A & NR & N/A & N/A \\
\hline Golimumab & 63,285 & 19.0 & 9.09 & 575,319 & 20.0 & 7.69 & 486,809 \\
\hline Sarilumab & 87,168 & 24.0 & 6.25 & 544,800 & 23.0 & 6.25 & 544,800 \\
\hline Tocilizumab & 27,350 & NR & N/A & N/A & 28.0 & 4.76 & 130,240 \\
\hline Tofacitinib & 58,996 & 21.0 & 7.69 & 453,818 & NR & N/A & N/A \\
\hline csDMARD & N/A & 8.0 & N/A & N/A & 7.0 & N/A & N/A \\
\hline \multicolumn{8}{|l|}{ ACR70 } \\
\hline Abatacept & 57,663 & 10.0 & 12.50 & 720,790 & 13.0 & 9.09 & 524,211 \\
\hline Adalimumab & 73,205 & NR & N/A & N/A & NR & N/A & N/A \\
\hline Baricitinib & 28,528 & 8.0 & 16.67 & 475,464 & 7.0 & 20.00 & 570,557 \\
\hline Certolizumab pegol & 65,711 & 7.0 & 20.00 & $1,314,228$ & NR & N/A & N/A \\
\hline Etanercept & 73,205 & NR & N/A & N/A & NR & N/A & N/A \\
\hline Golimumab & 63,285 & 7.0 & 20.00 & $1,265,703$ & 9.0 & 14.29 & 904,073 \\
\hline Sarilumab & 87,168 & 10.0 & 12.50 & $1,089,601$ & 10.0 & 12.50 & $1,089,601$ \\
\hline Tocilizumab & 27,350 & NR & N/A & N/A & 13.0 & 9.09 & 248,641 \\
\hline Tofacitinib & 58,996 & 9.0 & 14.29 & 842,805 & NR & N/A & N/A \\
\hline csDMARD & N/A & 2.0 & N/A & N/A & 2.0 & N/A & N/A \\
\hline
\end{tabular}

ACR American College of Rheumatology, ACR20/50/70 American College of Rheumatology 20\%/50\%/70\% improvement criteria, csDMARD conventional synthetic disease-modifying antirheumatic drug, $N / A$ not applicable, $N M A$ network meta-analysis, $N N T$ number needed to treat, $N R$ not reported

${ }^{a}$ The annual costs presented here assume $100 \%$ methotrexate use in combination with the primary therapy

${ }^{\mathrm{b}}$ Median ACR response rate estimated from the NMA (simultaneous fixed-effects, probit model)

remained robust across all one-way sensitivity analyses, as total cost and incremental PMPM values remained negative (cost saving). When considering updated 2018 real-world market shares, results trends remained similar.

\section{Discussion}

The results of this study illustrate that baricitinib is a costsaving treatment option for US payers. The efficacy of baricitinib was comparable to other subcutaneous biologics (abatacept, golimumab, tocilizumab, certolizumab pegol, and sarilumab) and tofacitinib (JAK inhibitor) and is less 
Table 6 Budget impact model results

\begin{tabular}{llllllll}
\hline Model result & \multicolumn{3}{l}{$\begin{array}{l}\text { Base Case 1: second-line after csD- } \\
\text { MARD (\$US) }\end{array}$} & & \multicolumn{2}{l}{$\begin{array}{l}\text { Base Case 2: third-line after csD- } \\
\text { MARD }\end{array}$} \\
\cline { 2 - 3 } & Year 1 & Year 2 & Year 1-2 & & Year 1 & Year 2 & Year 1-2 \\
\hline Overall cost to plan & $-24,688$ & $-145,053$ & $-169,742$ & & $-19,718$ & $-115,753$ & $-135,471$ \\
PMPM & 0.00 & -0.01 & -0.01 & & 0.00 & -0.01 & -0.01 \\
PMPY & -0.02 & -0.15 & -0.08 & & -0.02 & -0.12 & -0.07 \\
PPPM & -6 & -32 & -19 & & -5 & -25 & -15 \\
PPPY & -69 & -380 & -230 & & -55 & -304 & -184 \\
\hline
\end{tabular}

All costs correspond to 2019 US dollars

csDMARD conventional synthetic disease-modifying antirheumatic drug, PMPM per member per month, $P M P Y$ per member per year, $P P P M$ per patient per month, $P P P Y$ per patient per year expensive. Given comparable response rates across TNFis, JAKs, and non-TNFis, NNT values versus csDMARD were also similar across treatments. Baricitinib had the lowest cost per additional responder across all three ACR criteria at 12 weeks due to its comparable efficacy and low relative cost. At 24 weeks, baricitinib was second to tocilizumab for ACR20 and ACR50, and third to tocilizumab and abatacept for ACR70. Efficacy differences between baricitinib and tocilizumab are likely explained by differences in the underlying study populations and should be interpreted with caution. Tocilizumab reported a better response rate than baricitinib, although this may be due to differences in the study population. The patient population in the baricitinib trial had a longer duration of disease (14 years vs. 11.1 years for tocilizumab), higher proportion on prior non-TNFi (40\% vs. $0 \%$ for tocilizumab), and a higher proportion on more than three biologics than the other trials included in the NMA (29\% vs. value not reported for tocilizumab) [6, 53].

The NMA results are consistent with prior NMAs conducted in the TNFi-IR population, published before the availability of baricitinib, in that they also showed comparable efficacy across bDMARDs and tocilizumab [82-84]. A more recent NMA that included baricitinib $4 \mathrm{mg}$ (the approved dose in the European Union [85]), which was conducted as part of a technology appraisal guidance by NICE [48], also drew similar conclusions about comparable efficacy [86]. In that NMA, tocilizumab plus csDMARDs also showed better response rates than all other treatments (using the European League Against Rheumatism [EULAR] response criteria), although clinical experts highlighted that the tocilizumab trial had different characteristics than the trials for the other treatments and deemed tocilizumab to have similar efficacy to other bDMARDs [48].

Two prior BIMs related to the TNFi-IR population were published before the availability of baricitinib. The first BIM estimated the 5-year budget impact of sarilumab to US healthcare commercial payers by considering a patient population with moderate-to-severe RA and IR to csDMARDs or TNFis [49]. Overall, the analysis found that sarilumab was cost saving with a lower treatment cost and consistent dosing. The analysis highlighted the need for lower cost options in RA and the importance of considering claims-based analyses to understand real-world trends. While the second BIM was not directly comparable to the one presented here given differences in structure and purpose, the results are still relevant and insightful. In 2018, Claxton et al. [87] (an update of Claxton et al. [88]) investigated the economic impact of treatment cycling with DMARDs versus using a JAK inhibitor (tofacitinib) directly following methotrexate, or after methotrexate and one or two previous TNFis. The authors report that tofacitinib directly following methotrexate was associated with the lowest total 2-year costs, PMPM costs, and costs per ACR20/50 responder versus adalimumab and etanercept. Their study supports the notion that switching to another therapy with a different mechanism of action is potentially more cost saving than switching from one TNFi to another TNFi.

This study had several limitations that should be considered when interpreting the results. First, for the BIM, there was a lack of data on the number of patients who were csDMARD IRs among treated patients with moderate-to-severe RA. This value was derived from a retrospective analysis of the Corrona Rheumatoid Arthritis Disease Registry and was calculated as those with worsening or sustained moderate to high disease activity among those who initiated TNFis in the index period. This value was included in a one-way sensitivity analysis and did not impact trends. Second, current market share data are based on an analysis using commercial claims data, which tends to under-represent the $65+$ population and may not fully represent the csDMARD-IR population. Although the Truven Health MarketScan Research data are a limited sample, they do cover the entire US population, allowing for greater generalizability to the USA as opposed to using site-specific or regional data. Third, the BIM calculated drug acquisition costs based on assumptions on dosing and dose escalation. While dose escalation occurs on a per-patient basis, the model sought to capture these changes on overall costs over time using the best available 
(a) Posterior median difference in ACR20 response rate (with 95\% credible interval) of BARI 2-mg + csDMARD relative to active treatment at 12 weeks (simultaneous fixed-effects probit model) ${ }^{\mathrm{a}}$

CSDMARD

ABA 10-mg + csDMARD

GOL 50-mg + csDMARD

TOFA 5-mg + MTX

CZP + CSDMARD

SARI 200-mg + csDMARD

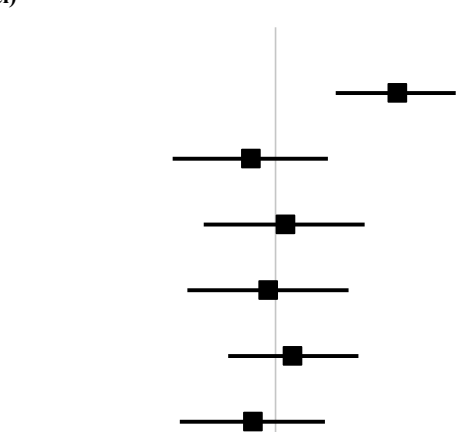

MTD $[95 \% \mathrm{Cr}-\mathrm{Int}]$

$21.2 \%[10.5 \% ; 31.3 \%]$

$-4.2 \%[-17.9 \% ; 9.1 \%]$

$1.7 \%[-12.5 \% ; 15.5 \%]$

$-1.2 \%[-15.3 \% ; 12.7 \%]$

$3.0 \%[-8.2 \% ; 14.4 \%]$

$-3.9 \%[-16.6 \% ; 8.6 \%]$

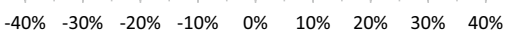

Posterior median difference (with 95\% Credible Interval)

(b) Posterior median difference in ACR50 response rate (with 95\% credible interval) of BARI 2-mg + csDMARD relative to active treatment at 12 weeks (simultaneous fixed-effects probit model)

CSDMARD

ABA 10-mg + csDMARD

GOL 50-mg + cSDMARD

TOFA 5-mg + MTX

$C Z P+\operatorname{csDMARD}$

SARI 200-mg + csDMARD

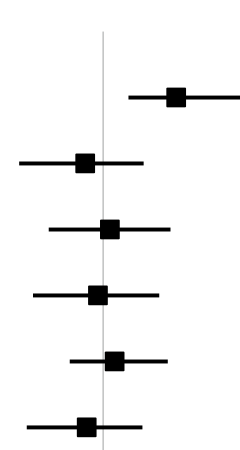

$\begin{array}{lllllllll}-40 \% & -30 \% & -20 \% & -10 \% & 0 \% & 10 \% & 20 \% & 30 \% & 40 \%\end{array}$

Posterior median difference (with 95\% Credible Interval)
MTD [95\% Cr-Int]

$12.7 \%$ [ $4.4 \% ; 23.8 \%]$

$-3.1 \%[-14.5 \% ; 7.0 \%]$

$1.2 \%[-9.4 \% ; 11.7 \%]$

$-0.9 \%[-12.1 \% ; 9.7 \%]$

$2.0 \%[-5.8 \% ; 11.2 \%]$

$-2.8 \%[-13.2 \% ; 6.8 \%]$

(c) Posterior median difference in ACR70 response rate (with 95\% credible interval) of BARI 2-mg + csDMARD relative to active treatment at 12 weeks (simultaneous fixed-effects probit model) ${ }^{\mathrm{a}}$

CSDMARD

ABA $10-m g+$ csDMARD

GOL 50-mg + csDMARD

TOFA 5-mg + MTX

$C Z P+$ CSDMARD

SARI 200-mg + csDMARD

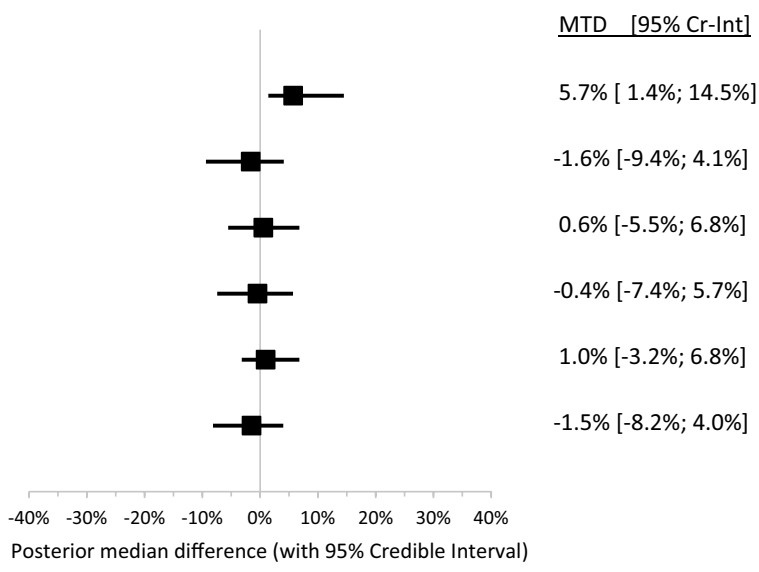

Fig. 2 ACR forest plots. a Posterior median difference in ACR20 (a), ACR50 (b), and ACR70 (c) response rate (with 95\% cr-Int) of BARI $2 \mathrm{mg}+\mathrm{csDMARD}$ relative to active treatment at 12 weeks (simultaneous fixed-effects probit model) and Posterior median difference in ACR20 (d), ACR50 (e), and ACR70 (f) response rate (with 95\% cr-Int) of BARI $2 \mathrm{mg}+\mathrm{csDMARD}$ relative to active treatment at 24 weeks (simultaneous fixed-effects probit model). Differences $>0$ are in favor of BARI $2 \mathrm{mg}+\mathrm{csDMARD}$, with the graph quantifying the median difference in ACR response in \% for BARI $2 \mathrm{mg}+\mathrm{csD}$ MARD relative to each comparator. $A B A$ abatacept, $A C R$ American College of Rheumatology, ACR20/50/70 American College of Rheumatology 20\%/50\%/70\% improvement criteria, BARI baricitinib, $\mathrm{Cr}$ Int credible interval, $c S D M A R D$ conventional synthetic disease-modifying antirheumatic drug, $C Z P$ certolizumab pegol, $G O L$ golimumab, $M T D$ median treatment difference, TCZ tocilizumab, TOFA tofacitinib, SARI sarilumab 
(d) Posterior median difference in ACR20 response rate (with 95\% credible interval) of BARI 2- mg + csDMARD relative to active treatment at 24 weeks (simultaneous fixed-effects probit model) ${ }^{\mathrm{a}}$

CSDMARD

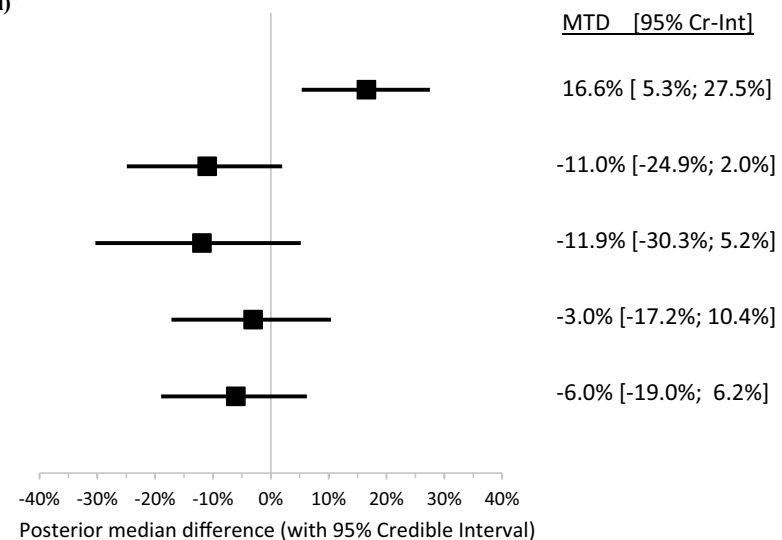

MTD $[95 \% \mathrm{Cr}-\operatorname{Int}]$

ABA 10-mg + csDMARD

(e) Posterior median difference in ACR50 response rate (with 95\% credible interval) of BARI 2-mg + csDMARD relative to active treatment at 24 weeks (simultaneous fixed-effects probit model) ${ }^{\mathrm{a}}$

CSDMARD

ABA 10-mg + csDMARD

TCZ 162-mg + csDMARD

GOL 50-mg + csDMARD

SARI 200-mg + csDMARD

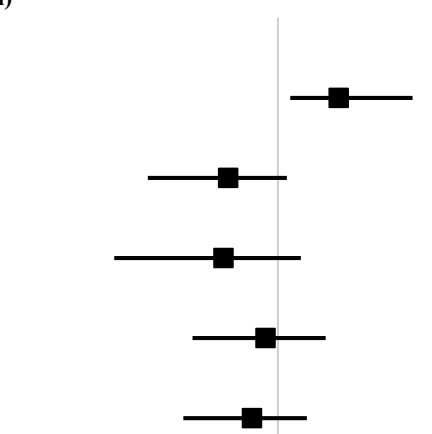

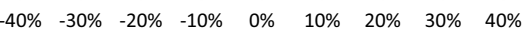

Posterior median difference (with 95\% Credible Interval)
MTD $[95 \% \mathrm{Cr}-\ln \mathrm{n}]$

$10.1 \%$ [ $2.0 \% ; 22.3 \%]$

$-8.2 \%[-21.5 \% ; 1.5 \%]$

$-9.0 \%[-27.1 \% ; 3.8 \%]$

$-2.0 \%[-14.1 \% ; 7.9 \%]$

$-4.3 \%[-15.7 \% ; 4.8 \%]$

(f) Posterior median difference in ACR70 response rate (with 95\% credible interval) of BARI 2-mg + csDMARD relative to active treatment at 24 weeks (simultaneous fixed-effects probit model) ${ }^{\mathrm{a}}$

CSDMARD

ABA 10-mg + csDMARD

TCZ 162-mg + csDMARD

GOL 50-mg + csDMARD

SARI 200-mg + csDMARD

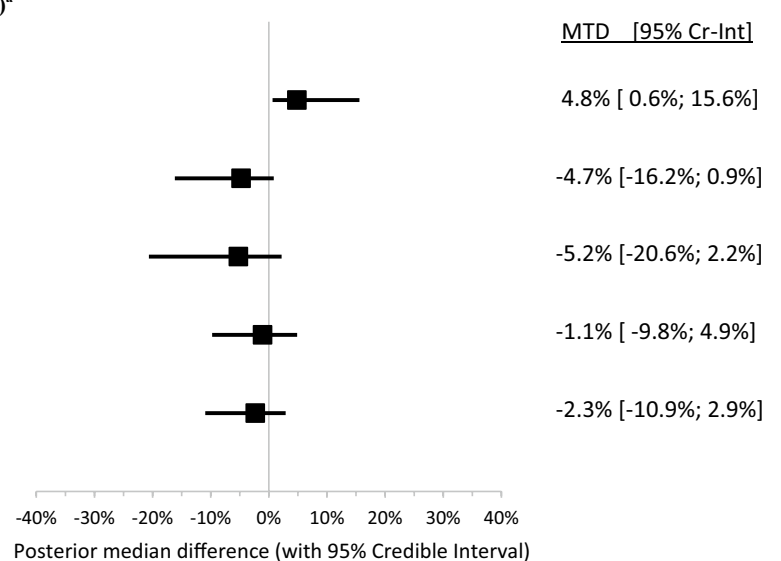

Posterior median difference (with 95\% Credible Interval)

${ }^{\mathrm{a}}$ Differences $>0$ are in favor of BARI 2-mg + csDMARD, with the graph quantifying the median difference in ACR response in $\%$ for BARI 2 -mg + csDMARD relative to each comparator.

ABA: abatacept; ACR: American College of Rheumatology; BARI: baricitinib; csDMARD: conventional synthetic disease-modifying antirheumatic drug; Cr-Int: credible interval; CZP: certolizumab pegol; GOL: golimumab; MTD: median treatment difference; TCZ: tocilizumab; TNFi: tumor necrosis factor inhibitor; TOFA: tofacitinib; SARI: sarilumab

Fig. 2 (continued)

evidence from the literature. Finally, for the NMA, crossstudy heterogeneity and the small number of studies on clinical performance limit the ability to draw clear conclusions.
Testing the effect of heterogeneity and for overall robustness though planned sensitivity analyses was not feasible due to the sparseness of the data. 


\section{Conclusion}

Baricitinib, compared with tsDMARDs and bDMARDs in the TNFi-IR population in this analysis, is a less expensive option with similar efficacy. Adding baricitinib to a formulary would likely be cost saving for US payers and expands treatment options for adult patients with moderately to severely active RA who have had an IR to one or more TNFis.

Acknowledgements Casey Choong (analyst, Eli Lilly and Company) conducted the claims-based analysis for the market shares.

\section{Compliance with Ethical Standards}

Funding This study was funded by Eli Lilly and Company. This study is available via Springer Open Choice, with the fee paid for by Eli Lilly and Company.

Conflict of interest Elizabeth Wehler, Oscar Herrera-Restrepo, and Stacey Kowal are employees of IQVIA who were hired by Eli Lilly and Company to conduct the analysis. Natalie Boytsov and Claudia Nicolay are employees and shareholders of Eli Lilly and Company.

Author contributions EW, SK, and NB developed the budget impact model along with number needed to treat and cost per responder calculations. $\mathrm{CN}$ developed the systematic literature review and network meta-analysis. OH-R collected data, performed computations, and consolidated results. All authors discussed the results and contributed to the final manuscript writing and revisions.

Data availability The datasets generated and/or analyzed during the current study are not publicly available as they contain proprietary data but are available from the corresponding author on reasonable request.

Open Access This article is distributed under the terms of the Creative Commons Attribution-NonCommercial 4.0 International License (http://creativecommons.org/licenses/by-nc/4.0/), which permits any noncommercial use, distribution, and reproduction in any medium, provided you give appropriate credit to the original author(s) and the source, provide a link to the Creative Commons license, and indicate if changes were made.

\section{References}

1. Kourilovitch M, Galarza-Maldonado C, Ortiz-Prado E. Diagnosis and classification of rheumatoid arthritis. J Autoimmun. 2014;48 49:26-30. https://doi.org/10.1016/j.jaut.2014.01.027.

2. Hunter TM, Boytsov NN, Zhang X, Schroeder K, Michaud K, Araujo AB. Prevalence of rheumatoid arthritis in the United States adult population in healthcare claims databases, 2004-2014. Rheumatol Int. 2017;37(9):1551-7. https://doi.org/10.1007/s0029 6-017-3726-1.

3. Smolen JS, Landewe R, Breedveld FC, Dougados M, Emery P, Gaujoux-Viala C, et al. EULAR recommendations for the management of rheumatoid arthritis with synthetic and biological diseasemodifying antirheumatic drugs. Ann Rheum Dis. 2010;69(6):96475. https://doi.org/10.1136/ard.2009.126532.
4. Singh JA, Saag KG, Bridges SL Jr, Akl EA, Bannuru RR, Sullivan MC, et al. 2015 American College of Rheumatology guideline for the treatment of rheumatoid arthritis. Arthritis Rheumatol. 2016;68(1):1-26. https://doi.org/10.1002/art.39480.

5. Smolen JS, Landewe R, Breedveld FC, Buch M, Burmester G, Dougados $\mathrm{M}$, et al. EULAR recommendations for the management of rheumatoid arthritis with synthetic and biological diseasemodifying antirheumatic drugs: 2013 update. Ann Rheum Dis. 2014;73(3):492-509. https://doi.org/10.1136/annrheumdis-2013204573.

6. Genovese MC, Kremer J, Zamani O, Ludivico C, Krogulec M, Xie L, et al. Baricitinib in patients with refractory rheumatoid arthritis. N Engl J Med. 2016;374(13):1243-52. https://doi. org/10.1056/NEJMoa1507247.

7. Blom M, Kievit W, Kuper HH, Jansen TL, Visser H, den Broeder AA, et al. Frequency and effectiveness of dose increase of adalimumab, etanercept, and infliximab in daily clinical practice. Arthritis Care Res (Hoboken). 2010;62(9):1335-41. https://doi. org/10.1002/acr.20211.

8. Karlsson JA, Kristensen LE, Kapetanovic MC, Gulfe A, Saxne T, Geborek P. Treatment response to a second or third TNF-inhibitor in RA: results from the South Swedish Arthritis Treatment Group Register. Rheumatology (Oxford). 2008;47(4):507-13. https://doi. org/10.1093/rheumatology/ken034.

9. Rendas-Baum R, Wallenstein GV, Koncz T, Kosinski M, Yang $\mathrm{M}$, Bradley J, et al. Evaluating the efficacy of sequential biologic therapies for rheumatoid arthritis patients with an inadequate response to tumor necrosis factor-alpha inhibitors. Arthritis Res Ther. 2011;13(1):R25. https://doi.org/10.1186/ar3249.

10. Kim HL, Lee MY, Park SY, Park SK, Byun JH, Kwon S, et al. Comparative effectiveness of cycling of tumor necrosis factoralpha (TNF-alpha) inhibitors versus switching to non-TNF biologics in rheumatoid arthritis patients with inadequate response to TNF-alpha inhibitor using a Bayesian approach. Arch Pharm Res. 2014;37(5):662-70. https://doi.org/10.1007/s12272-014-0337-1.

11. Alivernini S, Laria A, Gremese E, Zoli A, Ferraccioli G. ACR11disease activity score remission achievement from switches between all the available biological agents in rheumatoid arthritis: a systematic review of the literature. Arthritis Res Ther. 2009;11(6):R163. https://doi.org/10.1186/ar2848.

12. Ingham M, Ghushchyan VH, Reed G, Decktor D, Bolce R, Bolge $\mathrm{S}$, et al. Mapping health care costs to clinical disease activity where cost data is lacking - a novel approach using Medical Expenditure Panel Survey data with the Corrona Rheumatoid Arthritis Disease Registry [abstract no. PMS21]. Value Health. 2012;15(4):A37. https://doi.org/10.1016/j.jval.2012.03.210.

13. Beresniak A, Gossec L, Goupille P, Saraux A, Bamberger M, Bregman B, et al. Direct cost-modeling of rheumatoid arthritis according to disease activity categories in France. J Rheumatol. 2011;38(3):439-45. https://doi.org/10.3899/jrheum.100589.

14. Radner H, Smolen JS, Aletaha D. Remission in rheumatoid arthritis: benefit over low disease activity in patient-reported outcomes and costs. Arthritis Res Ther. 2014;16(1):R56. https://doi. org/10.1186/ar4491.

15. Curtis J, Chen L, Kilgore M, Yun H, Greenberg J. The clinical and economic costs of not achieving remission in rheumatoid arthritis. In: American College of Rheumatology/Association of Rheumatology Health Professionals annual meeting [abstract]; 10 Nov 2015; San Francisco. https://acrabstracts.org/abstract/theclinical-and-economic-costs-of-not-achieving-remission-in-rheum atoid-arthritis/

16. Gu N, Huang X-Y, Fox K, Patel V, Baumgartner S, Chiou C-F. Claims data analysis of dosing and cost of TNF antagonists. Am J Pharm Benefits. 2010;2(6):351-9.

17. Patel C, Tate N, Tao Z, Nadkarni A, Bruno A, Stembowski S, et al. Dosing patterns, healthcare costs, and provider characteristics 
in patients with rheumatoid arthritis being treated with biologic disease-modifying drugs (M02). J Manag Care Pharmacy. 2015;21(10 Suppl):S66. https://www.jmcp.org/doi/pdf/10.18553 /jmcp.2015.21.10.S1

18. Chastek B, Segal S, Bonafede R, Watson C, Becker L, Chaudhari $\mathrm{S}$, et al. Comparative effectiveness of TNF blockers in rheumatoid arthritis patients. Am J Pharm Benefits. 2013;5(Spec Iss):SP14-22.

19. Sullivan SD, Alfonso-Cristancho R, Carlson J, Mallya U, Ringold $\mathrm{S}$. Economic consequences of sequencing biologics in rheumatoid arthritis: a systematic review. J Med Econ. 2013;16(3):391-6. https://doi.org/10.3111/13696998.2013.763812.

20. Olumiant ${ }^{\circledR}$ (baricitinib) prescribing information. Indianapolis: Lilly USA, LLC; 2018 May.

21. Genovese M, Kremer J, Kartman C, Schilichting D, Xie L, Caramack T, et al. Previous biologic disease-modifying antirheumatic drug (bDMARD) exposure and efficacy and safety analysis from a phase 3 study of baricitinib in patients with rheumatoid arthritis and an inadequate response to tumor necrosis factor inhibitors. In: American College of Rheumatology/Association of Rheumatology Health Professionals annual meeting; 8 Nov 2015; San Francisco. http://pi.lilly.com/us/olumiant-uspi.pdf

22. Emery P, Blanco R, Maldonado Cocco J, Chen YC, Gaich CL, DeLozier AM, et al. Patient-reported outcomes from a phase III study of baricitinib in patients with conventional synthetic DMARD-refractory rheumatoid arthritis. RMD Open. 2017;3(1):e000410. https://doi.org/10.1136/rmdopen-2016-00041 0 .

23. Smolen J, DeLozer A, de Bono S, Yang L, Gaich C. Work productivity and daily activity in patients with rheumatoid arthritis in four phase III randomized clinical trials of baricitinib. In: European League Against Rheumatism (EULAR) annual meeting [abstract]; 8-11 Jun 2016; London. https://acrabstracts.org/abstr act/previous-biologic-disease-modifying-antirheumatic-drugbdmard-exposure-and-efficacy-and-safetyanalysis-from-a-phase -3-study-of-baricitinib-in-patients-with-rheumatoid-arthritis-andan-inadequate-re/

24. Sullivan SD, Mauskopf JA, Augustovski F, Caro J, Lee KM, Minchin M, et al. Budget impact analysis-principles of good practice: report of the ISPOR 2012 Budget Impact Analysis Good Practice II Task Force. Value Health. 2014;17(1):5-14. https:// doi.org/10.1016/j.jval.2013.08.2291.

25. US Census Bureau. Annual estimates of the resident population: April 1, 2010 to July 1, 2016. 2016 population estimates. https:// factfinder.census.gov/bkmk/table/1.0/en/PEP/2016/PEPANNRES. Accessed 16 Nov 2016.

26. Myasoedova E, Crowson CS, Kremers HM, Therneau TM, Gabriel SE. Is the incidence of rheumatoid arthritis rising? Results from Olmsted County, Minnesota, 1955-2007. Arthritis Rheum. 2010;62(6):1576-82. https://doi.org/10.1002/art.27425.

27. NCQA. Disease-modifying anti-rheumatic drug therapy for rheumatoid arthritis. http://www.ncqa.org/report-cards/health-plans/ state-of-health-care-quality/2017-table-of-contents/dmards. Accessed 3 Aug 2018

28. Jin Y, Desai RJ, Liu J, Choi NK, Kim SC. Factors associated with initial or subsequent choice of biologic disease-modifying antirheumatic drugs for treatment of rheumatoid arthritis. Arthritis Res Ther. 2017;19(1):159. https://doi.org/10.1186/s1307 5-017-1366-1.

29. Larmore CJ, Boytsov NN, Gaich CL, Zhang X, Araujo AB, Rebello S, et al. Examination of patient-reported outcomes in association with TNF-inhibitor treatment response: results from a US observational cohort study. Rheumatol Ther. 2018;5(1):21529. https://doi.org/10.1007/s40744-017-0092-0.

30. Catay E, Bravo M, Rosa J, Soriano ER. Prevalence of biologics monotherapy in a cohort of patients with rheumatoid arthritis in daily clinical practice. BMC Musculoskelet Disord. 2016;17:110. https://doi.org/10.1186/s12891-016-0959-1.

31. Soliman MM, Ashcroft DM, Watson KD, Lunt M, Symmons DP, Hyrich KL, et al. Impact of concomitant use of DMARDs on the persistence with anti-TNF therapies in patients with rheumatoid arthritis: results from the British Society for Rheumatology Biologics Register. Ann Rheum Dis. 2011;70(4):583-9. https://doi. org/10.1136/ard.2010.139774.

32. Actemra ${ }^{\circledR}$ (tocilizumab) prescribing information. San Francisco: Genentech Inc.; 2018 May.

33. Cimzia ${ }^{\circledR}$ (certolizumab pegol) prescribing information. Smyrna: UCB Inc.; 2018 Jun.

34. Humira ${ }^{\circledR}$ (adalimumab) prescribing information. North Chicago: AbbVie Inc.; 2017 Dec.

35. Kevzara ${ }^{\circledR}$ (sarilumab) prescribing information. Bridgewater Township: Sanofi-Aventis; 2018 Apr.

36. Orencia ${ }^{\circledR}$ (abatacept) prescribing information. New Brunswick: Bristol-Myers Squibb Company; 2017 Jun.

37. Enbrel $^{\circledR}$ (etarnecept) prescribing information. Newbury Park: Immunex Corporation; 2017 Nov.

38. Xeljanz ${ }^{\circledR}$ (tofacitinib) prescribing information. New York: Pfizer Labs; 2018 May.

39. Methotrexate prescribing information. Birmingham: Dava; 2016. https://www.accessdata.fda.gov/drugsatfda_docs/label /2016/008085s066lbl.pdf

40. Simponi ${ }^{\circledR}$ (golimumab) prescribing information. Horsham: Janssen Biotech; 2018 May.

41. Medispan Price Rx. https://pricerx.medispan.com/. Accessed Jul 2018.

42. Sangiorgi D, Benucci M, Nappi C, Perrone V, Buda S, Degli Esposti L. Drug usage analysis and health care resources consumption in naive patients with rheumatoid arthritis. Biologics. 2015;9:119-27. https://doi.org/10.2147/BTT.S89286.

43. Ferriols-Lisart R, Ferriols-Lisart F. Dose modifications of antiTNF drugs in rheumatoid arthritis patients under real-world settings: a systematic review. Rheumatol Int. 2015;35(7):1193-210. https://doi.org/10.1007/s00296-015-3222-4.

44. Curtis JR, Chastek B, Becker L, Quach C, Harrison DJ, Yun H, et al. Cost and effectiveness of biologics for rheumatoid arthritis in a commercially insured population. J Manag Care Spec Pharm. 2015;21(4):318-29. https://doi.org/10.18553/jmcp.2015.21.4.318.

45. Sato E, Tanaka E, Nakajima A, Inoue E, Shimizu Y, Yamaguchi $\mathrm{R}$, et al. Assessment of the effectiveness of golimumab 50-mg and 100-mg regimens in patients with rheumatoid arthritis in daily practice. Mod Rheumatol. 2015;25(4):528-33. https://doi. org/10.3109/14397595.2014.995892.

46. CMS. Clinical diagnostic laboratory fee schedule. 2018. https:// www.cms.gov/medicare/medicare-fee-for-service-payment/clini callabfeesched/clinlab.html. Accessed Jul 2018.

47. CMS. Physician fee schedule search. https://www.cms.gov/apps/ physician-fee-schedule/license-agreement.aspx. Accessed Jul 2018.

48. National Institute for Health and Care Excellence. Baricitinib for moderate to severe rheumatoid arthritis. London: NICE; 2017.

49. Ferrufino CP, Munakata J, Wei W, Proudfoot C, Kuznik A, Boklage $\mathrm{SH}$, et al. Budget impact analysis of sarilumab for the treatment of rheumatoid arthritis in patients with an inadequate response to conventional synthetic DMARD or TNF inhibitor therapies. Clinicoecon Outcomes Res. 2018;10:805-19. https:// doi.org/10.2147/CEOR.S163829.

50. Fleischmann R, St John G, Kimura T, Iglesias-Rodriguez M, Rosner I, Burmester GR. Sustained response in a phase 3 study of sarilumab plus nonbiologic disease-modifying antirheumatic drugs in patients with active, moderate-to-severe rheumatoid arthritis and inadequate response or intolerance to tumor necrosis factor inhibitors [abstract no. 2471]. Arthritis Rheumatol. 
2017;69. https://acrabstracts.org/abstract/sustained-response-ina-phase-3-study-of-sarilumab-plus-nonbiologicdisease-modif ying-antirheumatic-drugs-in-patients-with-active-moderate-tosevere-rheumatoid-arthritis-and-inadequate-response-or-in/

51. Genovese MC, Becker JC, Schiff M, Luggen M, Sherrer Y, Kremer J, et al. Abatacept for rheumatoid arthritis refractory to tumor necrosis factor alpha inhibition. N Engl J Med. 2005;353(11):1114-23. https://doi.org/10.1056/NEJMoa050524.

52. Westhovens R, Cole J, Li T, Martin M, Maclean R, Lin P, et al. Improved health-related quality of life for rheumatoid arthritis patients treated with abatacept who have inadequate response to anti-TNF therapy in a double-blind, placebo-controlled, multicentre randomized clinical trial. Rheumatology. 2006;45(10):1238-46.

53. Kivitz A, Olech E, Borofsky M, Zazueta BM, Navarro-Sarabia F, Radominski SC, et al. Subcutaneous tocilizumab versus placebo in combination with disease-modifying antirheumatic drugs in patients with rheumatoid arthritis. Arthritis Care Res (Hoboken). 2014;66(11):1653-61. https://doi.org/10.1002/acr.22384.

54. Strand V, Lampl K, Birchwood C, Pei J, Tuckwell K, Finch R, et al. FRI0253 Patient-reported outcomes in patients with rheumatoid arthritis treated with subcutaneous tocilizumab compared with placebo or intravenous tocilizumab in combination with csdmards. Ann Rheum Dis. 2017;76:581-2.

55. Smolen JS, Kay J, Doyle MK, Landewe R, Matteson EL, Wollenhaupt $\mathrm{J}$, et al. Golimumab in patients with active rheumatoid arthritis after treatment with tumour necrosis factor alpha inhibitors (GO-AFTER study): a multicentre, randomised, double-blind, placebo-controlled, phase III trial. Lancet. 2009;374(9685):210 21. https://doi.org/10.1016/S0140-6736(09)60506-7.

56. Burmester GR, Blanco R, Charles-Schoeman C, Wollenhaupt J, Zerbini C, Benda B, et al. Tofacitinib (CP-690,550) in combination with methotrexate in patients with active rheumatoid arthritis with an inadequate response to tumour necrosis factor inhibitors: a randomised phase 3 trial. Lancet. 2013;381(9865):451-60. https ://doi.org/10.1016/S0140-6736(12)61424-X.

57. Strand V, Burmester GR, Zerbini CA, Mebus CA, Zwillich SH, Gruben $\mathrm{D}$, et al. Tofacitinib with methotrexate in third-line treatment of patients with active rheumatoid arthritis: patient-reported outcomes from a phase III trial. Arthritis Care Res (Hoboken). 2015;67(4):475-83. https://doi.org/10.1002/acr.22453.

58. Genovese M, Kremer J, Zamani O, Ludivico C, Krogulec M, Xie L, et al. OP0029 Baricitinib, an oral janus kinase (JAK) 1/JAK2 inhibitor, in patients with active rheumatoid arthritis (RA) and an inadequate response to TNF inhibitors: results of the phase 3 RA-beacon study. Ann Rheum Dis. 2015;74:75-6.

59. Smolen J, Kremer J, Gaich C, DeLozier A, Schlichting D, Xie L, et al. SAT0349 patient-reported outcomes from a phase 3 study of baricitinib in patients with rheumatoid arthritis (RA) and an inadequate response to tumor necrosis factor inhibitors. Ann Rheum Dis. 2015;74:785-6.

60. Smolen JS, Kremer JM, Gaich CL, DeLozier AM, Schlichting $\mathrm{DE}, \mathrm{Xie} \mathrm{L}$, et al. Patient-reported outcomes from a randomised phase III study of baricitinib in patients with rheumatoid arthritis and an inadequate response to biological agents (RA-BEACON). Ann Rheum Dis. 2017;76(4):694-700.

61. Zamani O, Combe B, Tony H-P, Sanchez Burson J, Tahir H, Østergaard $\mathrm{M}$, et al. Efficacy and safety of baricitinib in patients with active rheumatoid arthritis and inadequate response to tumour necrosis factor inhibitors: summary results from the 24-week phase III RA-Beacon study [abstract no. 078]. Rheumatology. 2016;55(suppl_1):i93-i. https://doi.org/10.1093/rheumatology/ kew144.005.

62. Emery P, Keystone E, Tony HP, Cantagrel A, van Vollenhoven $\mathrm{R}$, Sanchez A, et al. IL-6 receptor inhibition with tocilizumab improves treatment outcomes in patients with rheumatoid arthritis refractory to anti-tumour necrosis factor biologicals: results from a 24-week multicentre randomised placebo-controlled trial. Ann Rheum Dis. 2008;67(11):1516-23. https://doi.org/10.1136/ ard.2008.092932.

63. Emery P, Fleischmann RM, Moreland LW, Hsia EC, Strusberg I, Durez P, et al. Golimumab, a human anti-tumor necrosis factor $\alpha$ monoclonal antibody, injected subcutaneously every four weeks in methotrexate-naive patients with active rheumatoid arthritis: twenty-four-week results of a phase III, multicenter, randomized, double-blind, placebo-controlled study of golimumab before methotrexate as first-line therapy for early-onset rheumatoid arthritis. Arthritis Rheum. 2009;60(8):2272-83.

64. Strand V, Burmester GR, Ogale S, Devenport J, John A, Emery P. Improvements in health-related quality of life after treatment with tocilizumab in patients with rheumatoid arthritis refractory to tumour necrosis factor inhibitors: results from the 24-week randomized controlled RADIATE study. Rheumatology (Oxford). 2012;51(10):1860-9. https://doi.org/10.1093/rheumatology/kes13 1 .

65. Weinblatt ME, Fleischmann R, Huizinga TW, Emery P, Pope J, Massarotti EM, et al. Efficacy and safety of certolizumab pegol in a broad population of patients with active rheumatoid arthritis: results from the REALISTIC phase IIIb study. Rheumatology (Oxford). 2012;51(12):2204-14. https://doi.org/10.1093/rheum atology/kes 150.

66. Pope J, Bingham CO 3rd, Fleischmann RM, Dougados M, Massarotti EM, Wollenhaupt J, et al. Impact of certolizumab pegol on patient-reported outcomes in rheumatoid arthritis and correlation with clinical measures of disease activity. Arthritis Res Ther. 2015;17:343. https://doi.org/10.1186/s13075-015-0849-1.

67. Cohen SB, Emery P, Greenwald MW, Dougados M, Furie RA, Genovese MC, et al. Rituximab for rheumatoid arthritis refractory to anti-tumor necrosis factor therapy: results of a multicenter, randomized, double-blind, placebo-controlled, phase III trial evaluating primary efficacy and safety at twenty-four weeks. Arthritis Rheum. 2006;54(9):2793-806.

68. Keystone E, Burmester GR, Furie R, Loveless JE, Emery P, Kremer $\mathbf{J}$, et al. Improvement in patient-reported outcomes in a rituximab trial in patients with severe rheumatoid arthritis refractory to anti-tumor necrosis factor therapy. Arthritis Rheum. 2008;59(6):785-93. https://doi.org/10.1002/art.23715.

69. Keystone E, Emery P, Peterfy CG, Tak PP, Cohen S, Genovese $\mathrm{MC}$, et al. Rituximab inhibits structural joint damage in patients with rheumatoid arthritis with an inadequate response to tumour necrosis factor inhibitor therapies. Ann Rheum Dis. 2009;68(2):216-21. https://doi.org/10.1136/ard.2007.085787.

70. Fleischmann R, van Adelsberg J, Lin Y, Castelar-Pinheiro GD, Brzezicki J, Hrycaj P, et al. Sarilumab and nonbiologic diseasemodifying antirheumatic drugs in patients with active rheumatoid arthritis and inadequate response or intolerance to tumor necrosis factor inhibitors. Arthritis Rheumatol. 2017;69(2):277-90. https ://doi.org/10.1002/art.39944.

71. Burmester G, Hrycaj P, Pacheco-Tena C, van Hoogstraten H, Mangan E, Lin Y, et al. SAT0168 Clinical remission outcomes with sarilumab plus csDMARDs in active, moderate-to-severe RA patients with inadequate response to tumor necrosis factor inhibitors. Ann Rheum Dis. 2016;75:727-8.

72. Fleischmann R, Castelar-Pinheiro G, Brzezicki J, Hrycaj P, Lin $\mathrm{Y}$, van Adelsberg J, et al. Efficacy and safety of sarilumab in combination with Csdmards in patients with active rheumatoid arthritis who were inadequate responders or intolerant of antiTNF-î \pm therapy: results from a phase 3 study [abstract no. 970]. Arthritis Rheum. 2015;67:1266-8.

73. Fleischmann R, Pinheiro GDRC, Brzezicki J, Hrycaj P, Lin Y, Adelsberg J, Graham N, et al. Efficacy and safety of sarilumab in combination with csDMARDs in patients with active rheumatoid 
arthritis who were inadequate responders or intolerant of antiTNF- $\alpha$ therapy: results from a phase 3 study [abstract no. ARAP96]. Int Med J. 2016;46(Suppl. 2):40-1.

74. Genovese Mda RC, Pinheiro G, Mangan E, Lin Y, van Adelsberg J, van Hoogstraten $\mathrm{H}$, et al. Efficacy of sarilumab plus csDMARDs in rheumatoid arthritis patients who had an inadequate response to one or more than one prior TNF inhibitor [poster no. SAT0174]. Ann Rheum Dis. 2016;75:730-1.

75. Strand V, Kosinski M, Graham N, Chen C-I, Joseph G, Bauer $\mathrm{D}$, et al. Impact of sarilumab on fatigue, pain, morning stiffness, productivity, and health related quality of life (HRQoL) in patients with active rheumatoid arthritis who were inadequate responders or intolerant of anti-TNF-Î \pm therapy: results from a phase 3 study (RCT) [abstract no. 435]. Arthritis Rheumatol. 2015;67:625-30.

76. Strand V, Reaney M, Chen CI, Proudfoot CW, Guillonneau S, Bauer D, et al. Sarilumab improves patient-reported outcomes in rheumatoid arthritis patients with inadequate response/ intolerance to tumour necrosis factor inhibitors. RMD Open. 2017;3(1):e000416. https://doi.org/10.1136/rmdopen-2016-00041 6.

77. Centre for Research and Dissemination (CRD). Systemic reviews: CRD's guidance for undertaking reviews in health care. 2009. http://www.york.ac.uk/inst/crd/index_guidance.htm. Accessed 7 Jun 2016.

78. NICE. National Institute for Health and Clinical Excellence. Methods for development of NICE public health guidance (3rd edition). 2012. https://www.nice.org.uk/article/pmg4/chapt er/1\%20introduction. Accessed 30 Jun 2016.

79. Dias S, Welton NJ, Sutton AJ, Ades AE. Evidence synthesis for decision making 1: introduction. Med Decis Making. 2013;33(5):597-606. https://doi.org/10.1177/0272989X1348760 4.

80. American College of Rheumatology Committee to Reevaluate Improvement Criteria. A proposed revision to the ACR1: the hybrid measure of American College of Rheumatology response. Arthritis Rheum. 2007;57(2):193-202. https://doi.org/10.1002/ art.22552.

81. Felson DT, Anderson JJ, Boers M, Bombardier C, Chernoff $\mathrm{M}$, Fried B, et al. The American College of Rheumatology preliminary core set of disease activity measures for rheumatoid arthritis clinical trials. The Committee on Outcome Measures in Rheumatoid Arthritis Clinical Trials. Arthritis Rheum. 1993;36(6):729-40.

82. Vieira MC, Zwillich SH, Jansen JP, Smiechowski B, Spurden $\mathrm{D}$, Wallenstein GV. Tofacitinib versus biologic treatments in patients with active rheumatoid arthritis who have had an inadequate response to tumor necrosis factor inhibitors: results from a network meta-analysis. Clin Ther. 2016;38(12):2628.e5-2641. e5. https://doi.org/10.1016/j.clinthera.2016.11.004.

83. Schoels M, Aletaha D, Smolen JS, Wong JB. Comparative effectiveness and safety of biological treatment options after tumour necrosis factor alpha inhibitor failure in rheumatoid arthritis: systematic review and indirect pairwise meta-analysis. Ann Rheum Dis. 2012;71(8):1303-8. https://doi.org/10.1136/annrheumdi s-2011-200490.

84. LeReun C, Neophytou I, De Vries R, Diamantopoulous A, Pompen M. A netowrk meta-analysis of biologic treatments in the TNF-IR rheumatoid artheritis patients. Value Health. 2012;14(7):A303.

85. European Medicines Agency. An overview of Olumiant and why it is authorised in the EU. London: European Medicines Agency, European Union; 2018.

86. Ren S, Bermejo I, Simpson E, Wong R, Scott DL, Young A, et al. Baricitinib for previously treated moderate or severe rheumatoid arthritis: an evidence review group perspective of a NICE single technology appraisal. Pharmacoeconomics. 2018;36(7):769-78. https://doi.org/10.1007/s40273-018-0616-7.

87. Claxton L, Taylor M, Soonasra A, Bourret JA, Gerber RA. An economic evaluation of tofacitinib treatment in rheumatoid arthritis after methotrexate or after 1 or 2 TNF inhibitors from a U.S. payer perspective. J Manag Care Spec Pharm. 2018;24(10):1010 7. https://doi.org/10.18553/jmcp.2018.17220.

88. Claxton L, Jenks M, Taylor M, Wallenstein G, Mendelsohn AM, Bourret JA, et al. An economic evaluation of tofacitinib treatment in rheumatoid arthritis: modeling the cost of treatment strategies in the United States. J Manag Care Spec Pharm. 2016;22(9):1088102. https://doi.org/10.18553/jmcp.2016.22.9.1088.

\section{Affiliations}

\section{Elizabeth Wehler ${ }^{1}$ (I) $\cdot$ Natalie Boytsov ${ }^{2} \cdot$ Claudia Nicolay $^{3} \cdot$ Oscar Herrera-Restrepo $^{4} \cdot$ Stacey Kowal $^{4}$}

1 IQVIA, 1 IMS Drive, Plymouth Meeting, PA 19462, USA

2 Eli Lilly and Company, Lilly Corporate Center, Indianapolis, IN 46285, USA

3 Lilly Deutschland GmbH, Bad Homburg, Germany
4 IQVIA, 3110 Fairview Park Drive, Falls Church, VA 22042, USA 